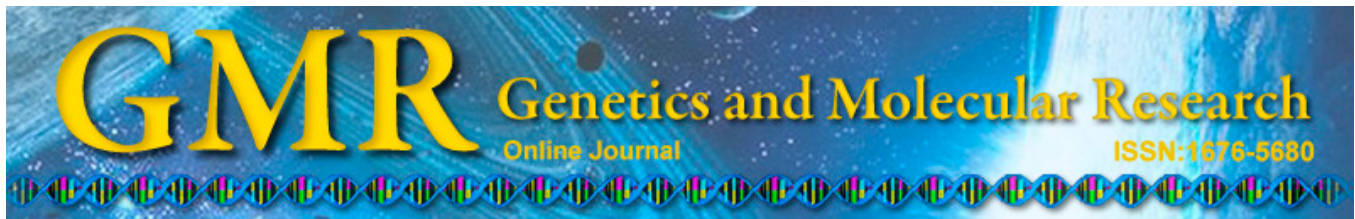

\title{
Association between RsaI polymorphism in estrogen receptor $\beta$ gene and male infertility
}

\section{B.M. Bordin and K.K.V.O. Moura}

Laboratório de Pesquisa REPLICON, Depertamento de Biomedicina e Farmácia, Pontifícia Universidade de Goiás, Goiânia, GO, Brasil

Corresponding author: B.M. Bordin

E-mail: barbarambordin@gmail.com

Genet. Mol. Res. 14 (3): 10954-10960 (2015)

Received February 17, 2015

Accepted June 14, 2015

Published September 21, 2015

DOI http://dx.doi.org/10.4238/2015.September.21.7

ABSTRACT. The estrogen receptor $\beta(E R \beta)$ gene plays an important role in the regulation of fertility in both males and females. The RsaI polymorphism in $E R \beta$ is associated with male infertility in Caucasian patients. The aim of this study was to investigate the frequency of this polymorphism in the etiology of idiopathic male infertility and its correlation with smoking habits. We analyzed 287 Brazilian men, including 161 infertile and 126 fertile men, to evaluate the association between the RsaI polymorphism and male infertility. The $R s a \mathrm{I}$ variant alleles of all patients were determined by allele-specific polymerase chain reaction. Compared with a control group (normozoospermic men), the frequency of the RsaI AG-genotype was four times higher in infertile men $(\mathrm{P}=0.01)$, five times higher in azoospermic men ( $\mathrm{P}$ $=0.02)$, and seven times higher in teratozoospermic men $(\mathrm{P}=0.001)$. The frequency of the RsaI AG-genotype was three times higher in infertile smokers $(\mathrm{P}=0.038)$ compared with infertile nonsmokers, and nine times higher in azoospermic smokers $(\mathrm{P}=0.035)$ compared with azoospermic nonsmokers. The RsaI polymorphism in $E R \beta$ may have modulating effects on human spermatogenesis. There seems to be a 
consistent association between $R s a \mathrm{I}$ polymorphism and smoking habits in infertile men.

Key words: $R s a$ I polymorphism; $E R \beta$ gene; Male infertility; Smoking habits

\section{INTRODUCTION}

Infertility is defined as a couple's inability to achieve pregnancy after one year of unprotected intercourse. Approximately $15 \%$ of couples face a problem conceiving (Huynh et al., 2002). A couple's ability to achieve pregnancy depends on several factors in both the male and female partners. Among all cases of infertility, about $20 \%$ can be traced to male factors, $40 \%$ can be traced to female factors, and $30 \%$ can be traced to factors in both the male and female partners. In about $15 \%$ of couples, the cause of the infertility cannot be traced to specific factors in either partner (Chandra and Gray, 1991). Various causative factors are responsible for male infertility, including varicocele, obstruction of the spermatic ducts, agglutination of sperm, impotency, hormonal imbalance, and genetic defects (Pryor et al., 1997). Based on the semen profile, male infertility is classified into four major categories, namely oligozoospermia (low sperm count), asthenozoospermia (low motility), teratozoospermia (abnormal shape and size), and azoospermia (complete absence ofsperm) (WHO, 1999). Genetic factors have been found to play a role in about 10\% of male infertility (Pryor et al., 1997).

The traditional view of estrogen as the "female" hormone and of testosterone as the "male" hormone has been challenged in recent years (Sharpe, 1998; O'Donnell et al., 2001). In males, the estrogen level is high in semen. Estrogens are synthesized from testosterone via the action of aromatase cytochrome P450 (Simpson et al., 1994). Estrogens seem to play an important role in male fertility, as demonstrated by the discovery that aromatase deficiency causes progressive infertility in adult mice (Robertson et al., 1999) and reduced production and motility in human sperm (Carani et al., 1997; Herrmann et al., 2002); there is evidence pointing to a direct effect on the function of Leydig cells and the efferent ductule epithelium, and also potential effects on germ cells (Hess et al., 1997).

Estrogen signaling in the cell is mediated by estrogen receptors, of which at least two subtypes exist: ER $\alpha$ and ER $\beta$. Recently, several sequence variants of the $E R \beta$ gene have been described (Rosenkranz et al., 1998), including the silent RsaI polymorphism that has been overrepresented in ovulatory dysfunctions. This polymorphism comprises the exchange of nucleotide $\mathrm{G}$ for nucleotide $\mathrm{A}$ at position 1082 in exon 5 of the $E R \beta$ gene, on the long arm of chromosome 14 (Sundarrajan et al., 2001). The RsaI polymorphism of $E R \beta$ is associated with male infertility in Caucasian patients (Aschim et al., 2005).

Research has shown that men who smoke cigarettes may have higher levels of sperm of an abnormal appearance, and show evidence of DNA damage. Smoking has also been associated with alterations in hormone levels in males; for example, increases in the levels of estrone and estradiol (Vine, 1996).

Studies on genetic variants of $E R \beta$ with respect to male infertility are scarce. Such information might add to our knowledge regarding the role of estrogens in the physiology and pathophysiology of male reproductive systems. Accordingly, our aim was to investigate the $R s a \mathrm{I}$ polymorphism of $E R \beta$ with respect to male infertility and smoking habits. Furthermore, by comparing spermogram phenotypes with different $E R \beta$ genotypes, we wished to evaluate whether these polymorphic forms might play a role in ER $\beta$ function in vivo. 


\section{MATERIAL AND METHODS}

\section{Subjects and controls}

The project was approved by the Ethics in Research Committee of the Pontifícia Universidade de Goiás (No. 347/2005). In total, 287 Brazilian men were chosen for this study, including 161 infertile men, and 126 fertile men used as a control (normal spermograms). The group of infertile men included 44 azoospermic, 43 oligozoospermic, 29 asthenozoospermic, and 45 teratozoospermic subjects. Men with known genetic causes of infertility, e.g., Klinefelter syndrome or Y-chromosome microdeletions, as well as those with a history of cryptorchidism were excluded. Samples of blood were collected at the Laboratory of Human Reproduction of the Clinical Hospital of the Federal University of Goiás. The patients were classified according to alterations detected in three consecutive spermograms, based on the WHO technique (1999).

\section{DNA isolation and molecular analysis}

Genomic DNA was isolated from peripheral blood lymphocytes following the manufacturer instructions for the GFX Genomic Blood DNA purification kit (Amersham Pharmacia Biotech Inc., Piscataway, NJ, USA).

Allele-specific polymerase chain reaction (PCR) was performed to detect the $R s a \mathrm{I}$ variants of $E R \beta$. Two reactions per subject were run, using a specific primer for either the polymorphic A variant or for the wild-type $\mathrm{G}$ variant, together with an upstream and a downstream primer. PCR conditions were established to generate both a control fragment and a shorter, allele-specific band in the presence of the variant, and the control fragment alone the absence of the variant (Aschim et al., 2005).

Allele-specific PCR of the RsaI polymorphism was performed in a total volume of $25 \mu \mathrm{L}$ containing $100 \mathrm{ng}$ genomic DNA, $45 \mathrm{mM} \mathrm{KCl}, 10 \mathrm{mM}$ TrisHCl, $\mathrm{pH}$ 9.0, 0.1\% Tween 20, $0.2 \mathrm{mM}$ deoxynucleotide triphosphate, $1.5 \mathrm{mM} \mathrm{MgCl}, 1 \mathrm{U}$ DyNAzyme Taq polymerase (FinnzymesOy, Espoo, Finland), and $0.5 \mu \mathrm{M}$ of each primer: RsaI forward ( $\mathrm{Fw})$, RsaI reverse (Rev-control), and either RsaI RevA or RsaI RevG. Primer sequences are presented in Table 1.

\section{Table 1. Primer sequences.}

\begin{tabular}{lll}
\hline Primer & Sequences (5'-3') & Fragment length (bp) \\
\hline RsaI Fw & ACT TGC CAT TCT GTC TCT ACA & \\
RsaI Rev & CAC AGG ACC CTG AAT CCT & 409 (control) \\
RsaI RevA & AGC TCT CCA AGA GCC GT & 127 (A - variant) \\
Rsal RevG & AGC TCT CCA AGA GCC GC & 127 (G - variant) \\
\hline
\end{tabular}

Amplification was performed for 35 cycles, with each cycle including denaturation for $1 \mathrm{~min}$ at $96^{\circ} \mathrm{C}$, primer annealing for $30 \mathrm{~s}$ at $58^{\circ} \mathrm{C}$, and primer extension for $3 \mathrm{~min}$ at $72^{\circ} \mathrm{C}$, with an initial denaturation step for $3 \mathrm{~min}$ at $96^{\circ} \mathrm{C}$, and a final extension step for $7 \mathrm{~min}$ at $72^{\circ} \mathrm{C}$. The control fragment and the allele-specific fragment comprised 409 and $127 \mathrm{bp}$, respectively. The PCR product was subjected to electrophoresis on a $1.5 \%$ agarose gel impregnated with 5 $\mu \mathrm{g} / \mathrm{mL}$ ethidiumbromide and visualized under ultraviolet light. 


\section{Statistical analysis}

The distributions of $E R \beta$ polymorphisms were compared between the patient groups and controls using the Fisher exact test applying the LH Start statistical software (version 3.5). All statistical tests were two sided. $\mathrm{P}<0.05$ was considered to be statistically significant.

\section{RESULTS}

The RsaI AA genotype was not found in either fertile or infertile men. The analysis showed that the infertile men had an approximately four times higher frequency of the heterozygous RsaI AG genotype ( 9.94 vs $2.38 \%$; $\mathrm{P}=0.01$ ) compared with the controls. In the group of infertile men, azoospermic men had an approximately five times higher frequency of the heterozygous $R s a \mathrm{I}$ AG genotype (11.36 vs 2.38\%; $\mathrm{P}=0.02)$, and teratozoospermic men had an approximately seven times higher frequency $(17.79$ vs $2.38 \% ; \mathrm{P}=0.001)$ compared with the controls. Oligozoospermic men had an approximately three times higher frequency of the heterozygous RsaI AG genotype than the controls, but did not show statistical significance. The genotype RsaI AG was not found in the asthenozoospermic men (Table 2).

\begin{tabular}{|c|c|c|c|c|}
\hline \multirow[t]{2}{*}{ Category of samples } & \multicolumn{3}{|c|}{$R s a \mathrm{I}$} & \multirow[t]{2}{*}{$\mathrm{P}$} \\
\hline & $\mathrm{AA}(\%)$ & AG $(\%)$ & GG (\%) & \\
\hline Normal $(\mathrm{N}=126)$ & $0(0)$ & $3(2.38)$ & $123(97.62)$ & \\
\hline Total Infertile & $0(0)$ & $16(9.94)$ & $145(90.06)$ & 0.010 \\
\hline \multicolumn{5}{|l|}{ Infertile } \\
\hline Azoospermic $(\mathrm{N}=44)$ & $0(0)$ & $5(11.36)$ & $39(88.64)$ & 0.020 \\
\hline Oligozoospermic $(\mathrm{N}=43)$ & $0(0)$ & $3(6.98)$ & $40(93.02)$ & 0.330 \\
\hline Astenozoospermic $(\mathrm{N}=29)$ & $0(0)$ & $0(0)$ & $29(100)$ & 1.000 \\
\hline Teratozoospermic $(\mathrm{N}=45)$ & $0(0)$ & $8(17.79)$ & $37(82.21)$ & 0.001 \\
\hline
\end{tabular}

In the group of infertile men, smokers had an approximately three times higher frequency of the heterozygous RsaI AG genotype ( $23.8 v s 7.4 \% ; \mathrm{P}=0.038$ ) than nonsmokers. In the group of azoospermic men, the frequency of the heterozygous $R s a \mathrm{I} A G$ genotype was approximately nine times higher in smokers (66.7 vs 6.9\%; $\mathrm{P}=0.035)$ compared with nonsmokers (Table 3 ).

Table 3. Distribution of the RsaI genotypes and correlation between sperm phenotypes and smoking habits.

\begin{tabular}{|c|c|c|c|c|c|c|c|c|c|c|c|c|}
\hline \multirow[t]{2}{*}{ Groups } & \multicolumn{3}{|c|}{ Normal } & \multicolumn{3}{|c|}{ Azoopermic } & \multicolumn{3}{|c|}{ Oligozoopermic } & \multicolumn{3}{|c|}{ Teratozoopermic } \\
\hline & $\mathrm{N}$ & AG (\%) & GG (\%) & $\mathrm{N}$ & AG (\%) & GG (\%) & $\mathrm{N}$ & AG (\%) & GG (\%) & $\mathrm{N}$ & AG (\%) & GG $(\%)$ \\
\hline \multicolumn{13}{|l|}{ Smoke } \\
\hline Yes & 16 & $0(0)$ & $16(100)$ & 3 & $2(66.7)$ & $1(33.3)$ & 7 & $1(14.3)$ & $6(85.7)$ & 8 & $2(25)$ & $6(75)$ \\
\hline No & 69 & $1(1.5)$ & $68(98.5)$ & 29 & $2(6.9)$ & $27(93.1)$ & 25 & $2(8)$ & $23(92)$ & 33 & $4(12.1)$ & $29(87.9)$ \\
\hline $\mathrm{P}$ & 1 & & & 0.035 & & & 0.993 & & & 0.577 & & \\
\hline
\end{tabular}

In oligozoospermic men, there was no significant difference between the frequencies of the heterozygous $R s a \mathrm{I}$ AG genotype in smokers and nonsmokers $(\mathrm{P}=0.993)$. In teratozoospermic men, the frequency of the AG genotype in smokers was approximately two times higher than that in nonsmokers, but the difference in these frequencies between smokers and nonsmokers was not significant $(\mathrm{P}=0.577)$ (Table 3$)$. 


\section{DISCUSSION}

Male infertility is related to male causative factors and is the inability to achieve pregnancy after 1 year of unprotected intercourse. Approximately $15 \%$ of couples attempting their first pregnancy experience some failure. Male causative factors are solely associated with infertility in $30 \%$ of cases, and an additional $20 \%$ of infertility cases result from combined male and female factors. Therefore, a male causative factor is associated with approximately $50 \%$ of all infertility (Demetrius, 2006).

In recent years, knowledge about the genetic etiology of infertility has increased thanks to advances in this field, because different genetic abnormalities have been identified, which considerably contribute to resolving the etiology of this problem (Maegawa and Centa, 2000).

Research has only recently identified the genes involved in the regulation of spermatogenesis. The increasing knowledge of the human genome and the genes that control human reproduction is fundamental to the study of fertility (Lahn and Page, 1997). Recent research has produced a growing body of evidence suggesting that estrogen should be added to the list of hormones involved in the regulation of spermatogenesis, which has for many years been known to be regulated by follicle-stimulating hormone and androgen (O'Donnell et al., 2001).

Aschim et al. (2005) were the first to perform studies showing an association between genetic variants of the gene for $E R \beta$ and male infertility, and found that the frequency of the $R s a \mathrm{I}$ AG genotype of $E R \beta$ was increased in infertile men, compared with a control group.

Our study found that the frequency of the RsaI AG genotype of the gene for $E R \beta$ in men with azoospermia, oligozoospermia, asthenozoospermia, or teratozoospermia is about four times higher than that in normal men following the results of the spermogram. Among the changes, it was found that the frequency of the RsaI AG genotype of the gene $E R \beta$ is about five times higher in azoospermia, approximately 7.5 times higher in teratozoospermia, and three times higher in oligozoospermia compared to the second report of a normal spermogram. In oligozoospermia there was no statistical significance, which may be due to low statistical power resulting from small samples.

These data are consistent with the research conducted by Aschim et al. (2005), which reported a frequency of the $R s a \mathrm{I} A G$ genotype of $E R \beta$ that was three times higher in infertile men compared with the controls. In the Aschim et al. (2005) study, men were classified according to spermogram, and only the change in the number of sperm was observed; therefore, in the present study, we also examined the sperm morphology and motility. In this study the men were classified as infertile if their sperm concentration was below $5 \times 10^{6} / \mathrm{mL}$ of ejaculate (severe oligozoospermic) and the control group comprised those with sperm concentrations higher than $5 \times 10^{6} / \mathrm{mL}$ of ejaculate, which also included those with non-severe oligozoospermia, i.e., with sperm concentrations of $5-20 \times 10^{6} / \mathrm{mL}$ of ejaculate.

Our findings are consistent with the observation of increased risk of a reduction of sperm quality in subjects exposed to diethylstilbestrol in the uterus (Gill et al., 1977). Furthermore, studies show that suspension of spermatogenesis occurs when men are subject to long-term estrogen therapy before sex change surgery (Schulze, 1988; Aschim et al., 2004), and it therefore seems reasonable to suggest that greater exposure to estrogen reduces spermatogenesis (Aschim et al., 2005).

The mechanisms involved in the altered gene function in subjects with genotype ERßAG of the RsaI polymorphism have not yet been elucidated. The change from "G" to "A" does not lead to a change of amino acids in the protein. One can speculate, however, that this 
polymorphism is in disequilibrium with other genetic variations that may affect gene expression or function (Aschim et al., 2005).

In our study, we also found from the spermograms that the frequency of the AG genotype of the $R s a \mathrm{I}$ polymorphism of $E R \beta$ was three times higher in smokers than in nonsmokers. The frequency of the $R s a \mathrm{I}$ AG genotype of the $E R \beta$ gene was 9.7 times higher in smokers than nonsmokers with azoospermia. Exposure to drugs and environmental toxins can alter spermatogenesis directly or through the endocrine system. Pesticides, sulfasalazine, nitrofurantoin, cimetidine, caffeine, nicotine, alcohol, and marijuana have been listed as gonadotoxic agents (Lipshultz et al., 1980). Although the results of clinical studies that have tried to correlate smoking as a cause of male infertility are heterogeneous, there is enough cumulative evidence to establish the relationship; smoking is responsible for changes in sperm motility and morphology, is a depressor of spermatogenesis (Thompson, 1994), and changes hormone levels (Vine, 1996). Pasqualotto et al. (2006) reported that smoking may alter levels of serum testosterone and estradiol, and change sperm DNA.

Our study adds to the scarce literature on idiopathic male infertility by using a pioneering analysis of the $R s a \mathrm{I}$ polymorphism in the $E R \beta$ gene, in which men were stratified into groups according to the results from their individual spermograms. Research correlating smoking to infertility is also scarce and sometimes controversial. Our study is the first to relate the $R s a \mathrm{I}$ polymorphism of the $E R \beta$ gene with smoking. Male infertility still requires a great deal of study and elucidation, especially with regards to understanding the genetic mechanisms governing the human male physiology.

Currently, the majority of cases of male infertility may be overcome by techniques in assisted reproduction. This makes tests for the detection of chromosome disorders and genetic changes the fundamental focus for infertility research. There are several reasons for screening in infertile men, such as the fact that some genetic disorders are incompatible with fertilization, and and highly heritable genetic disorderschange to their children may result in male infertility or genetic abnormalities in the offspring. These risks must be assessed before fertilization is attempted because fertilization with sperm from a donor might be a better alternative for many couples.

\section{ACKNOWLEDGMENTS}

\section{PROPE).}

Research supported by Universidade Católica de Goiás, Goiânia, GO, Brazil (\#UCG/

\section{REFERENCES}

Aschim EL, Saether T, Wiger R, Grotmol T, et al. (2004). Differential distribution of splice variants of estrogen receptor beta in human testicular cells suggests specific functions in spermatogenesis. J. Steroid Biochem. Mol. Biol. 92: $97-$ 106.

Aschim EL, Giwercman A, Ståhl O, Eberhard J, et al. (2005). The RsaI polymorphism in the estrogen receptor-beta gene is associated with male infertility. J. Clin. Endocrinol. Metab. 90: 5343-5348.

Carani C, Qin K, Simoni M, Faustini-Fustini M, et al. (1997). Effect of testosterone and estradiol in a man witharomatase deficiency. N. Engl. J. Med. 337: 91-95.

Chandra A and Gray RH (1991). Epidemiology of infertility. Curr. Opin. Obst. Gynecol. 2: 154-158.

Demetrius JP (2006). Male infertility: etiology, history, and physical assessment. J. Nurse Practitioners 2: 226-228.

Gill WB, Schumacher GF and Bibbo M (1977). Pathological semen and anatomical abnormalities of the genital tract in human male subjects exposed to diethylstilbestrol in utero. J. Urol. 117: 477-480. 
Herrmann BL, Saller B, Janssen OE, Gocke P, et al. (2002). Impact of estrogen replacement therapy in a male with congenital aromatase deficiency caused by a novel mutation in the CYP19 gene. J. Clin. Endocrinol. Metab. 87: 5476-5484.

Hess RA, Bunick D, Lee KH, Bahr J, et al. (1997). A role for oestrogens in the male reproductive system. Nature 390: 509-512.

Huynh T, Mollard R and Trounson A (2002). Selected genetic factors associated with male infertility. Hum. Reprod. Update 8: 183-198.

Lahn BT and Page DC (1997). Functional coherence of the human Y chromosome. Science 278: 675-680.

Lipshultz LI, Ross CE, Whorton D, Milby T, et al. (1980). Dibromochloropropane and its effect on testicular function in man. J. Urol. 124: 464-468.

Maegawa GHB and Centa LJR (2000). Aspectos genéticos do fator masculino na infertilidade. Fam. Saúde Desenv., Curitiba, v.2, n.1, p.7-12, jan./jun. 2000.

O’Donnell L, Robertson KM, Jones ME and Simpson ER (2001). Estrogen and spermatogenesis. Endocr. Rev. 22: 289318.

Pasqualotto FF, Sobreiro BP, Hallak J, Pasqualotto EB, et al. (2006). Cigarette smoking is related to a decrease in semen volume in a population of fertile men. BJU Int. 97: 324-326.

Pryor JL, Kent-First M, Muallem A, Van Bergen AH, et al. (1997). Microdeletions in the Y chromosome of infertile men. New Engl. J. Med. 336: 534-539.

Robertson KM, O’Donnell L, Jones ME, Meachem SJ, et al. (1999). Impairment of spermatogenesisin mice lacking a functional aromatase (cyp19) gene. Proc. Natl. Acad. Sci. U. S. A. 96: 7986-7991.

Rosenkranz K, Hinney A, Ziegler A, Hermann H et al. (1998). Systematic mutation screening of the estrogen receptor beta gene in probands of different weight extremes: identification of several genetic variants. J. Clin. Endocrinol. Metab. 83: 4524-4527.

Schulze C (1988). Response of the human testis to long-term estrogen treatment: morphology of Sertoli cells, Leydig cells and spermatogonial stem cells. Cell Tissue Res. 251: 31-43.

Sharpe RM (1998). The roles of oestrogen in the male. Trends Endocrinol. Metab. 9: 371-377.

Simpson ER, Mahendroo MS, Means GD, Kilgore MW, et al. (1994). Aromatase cytochrome P450, the enzyme responsible for estrogen biosynthesis. Endocr. Rev. 15: 342-355.

Sundarrajan C, Liao WX, Roy AC and Ng SC (2001). Association between estrogen receptor-beta gene polymorphisms and ovulatory dysfunctions in patients with menstrual disorders. J. Clin. Endocrinol. Metab. 86: 135-139.

Thompson ST (1994). Prevention of male infertility: an update. Urol. Clin. North Am. 21: 365-376.

Vine MF (1996). Smoking and male reproduction: a review. Int. J. Androl. 19: 323-337.

World Health Organization (WHO) (1999). Laboratory Manual for the Examination of Human Semen and Semen-Cervical Mucus Interaction. 4th edn. The Press Syndicate of the University of Cambridge. 